Marcelo Bessa de Freitas 1

\title{
Importância da análise de água para a saúde pública em duas regiões do Estado do Rio de Janeiro: enfoque para coliformes fecais, nitrato e alumínio
}

\author{
The importance of water testing for public \\ health in two regions in Rio de Janeiro: a focus \\ on fecal coliforms, nitrates, and aluminum
}

\footnotetext{
1 Núcleo de Estudos de Saúde Coletiva, Universidade

Federal do Rio de Janeiro. Av. Brigadeiro Trompowski s/no, Hospital Universitário Clementino Fraga Filho, 5o andar, Ala Sul, Rio de Janeiro, $R J$ 21931-059, Brasil. bessabr@brfree.com.br 2 Urban Environmental Department, Institute of Urban Studies. Burg. Oudlaan 50, J-Building, Rotterdam, Holland. 3 Departamento de Saneamento e Saúde Ambiental, Escola Nacional de Saúde Pública Fundação Oswaldo Cruz. Rua Leopoldo Bulhões 1480 50 andar, Rio de Janeiro, $R$ 21041-210, Brasil.
}

\begin{abstract}
In developing countries, due to poor sanitation conditions and poor quality of drinking water, typical water-borne diseases and more recently diseases caused by drinking water with high concentrations of nitrates and certain metals like aluminum have increased the concern over the health effects of these compounds. Several articles have shown associations between nitrates and methemoglobinemia in children, and aluminum and Alzheimer disease in adults. This study identified water quality with several parameters in non-conformity with Brazilian drinking water standards (Ruling 36/90): more than 50\% of all samples from both regions contained fecal coliforms; some $31 \%$ of water samples from wells in Duque de Caxias had excessive nitrate concentrations; $100 \%$ of all groundwater samples from both regions showed aluminum concentrations not conforming to the norm, with the same result for $100 \%$ of samples from the drinking water distribution system in São Gonçalo and 75\% of same in Duque de Caxias. This lack of conformity poses several health risks for the local population.
\end{abstract}

Key words Coliforms; Colimetry; Water Quality; Water Analysis

Resumo Nos países em desenvolvimento, onde ainda podemos encontrar áreas urbanas densamente povoadas com precárias condições de saneamento básico, a água é responsável por um grande número de doenças de veiculação hídrica. Vários artigos têm apontado para as doenças causadas pelas altas concentrações de nitrato e alumínio na água, tais como a metemoglobinemia e Mal de Alzheimer, respectivamente. Este estudo mostrou que a qualidade da água de poço e de rede, consumidas em duas micro-regiões dos municípios de Duque de Caxias e São Gonçalo apresentou várias não conformidades com a Portaria 36/90: mais de 50\% das amostras de água de poço nas duas áreas apresentaram contaminação por coliformes fecais; cerca de $31 \%$ das amostras de água de poço de Duque de Caxias apresentaram níveis de nitrato acima do valor máximo permissivel; 100\% das amostras de água de rede das duas regiões apresentaram concentrações de alumínio acima da norma; mesmo resultado em 100\% das amostras de água de poço em São Gonçalo e 75\% em Duque de Caxias. Estas não conformidades podem representar possíveis riscos à saúde dessas populações.

Palavras-chave Coliformes; Colimetria; Qualidade da Água; Análise da Água 


\section{Introdução}

Apesar de todos os esforços para armazenar e diminuir o seu consumo, a água está se tornando, cada vez mais, um bem escasso, e sua qualidade se deteriora cada vez mais rápido.

A água subterrânea, por exemplo, além de ser um bem econômico, é considerada mundialmente uma fonte imprescindível de abastecimento para consumo humano, para as populações que não têm acesso à rede pública de abastecimento ou para aqueles que, tendo acesso a uma rede de abastecimento, têm o fornecimento com freqüência irregular. No Brasil, o aqüífero subterrâneo abastece 6.549.363 domicílios ( $19 \%$ do total), e, destes, $68,78 \%$ estão localizados na área rural, abrangendo $11,94 \%$ de toda a população nacional (IBGE, 1994).

As fontes de contaminação antropogênica em águas subterrâneas são em geral diretamente associadas a despejos domésticos, industriais e ao chorume oriundo de aterros de lixo que contaminam os lençóis freáticos com microorganismos patogênicos (Freitas \& Almeida, 1998). Além de promoverem a mobilização de metais naturalmente contidos no solo, como alumínio, ferro e manganês (Nordberg et al., 1985), também são potenciais fontes de nitrato e substâncias orgânicas extremamente tóxicas ao homem e ao meio ambiente.

Os constituintes químicos das águas subterrâneas podem ser influenciados por vários fatores, entre os quais deposição atmosférica, processos químicos de dissolução e/ou hidrólise no aqüífero e mistura com esgoto e/ou águas salinas por intrusão, fatores esses que modificam as características qualitativas e quantitativas dos mananciais subterrâneos.

Nos sistemas de distribuição de água potável, a qualidade desta pode sofrer uma série de mudanças, fazendo com que a qualidade da água na torneira do usuário se diferencie da qualidade da água que deixa a estação de tratamento. Tais mudanças podem ser causadas por variações químicas e biológicas ou por uma perda de integridade do sistema (Deininger et al. 1992).

Alguns fatores que influenciam tais mudanças incluem: (1) qualidade química e biológica da fonte hídrica; (2) eficácia do processo de tratamento, reservatório (armazenagem) e sistema de distribuição; (3) idade, tipo, projeto e manutenção da rede; (4) qualidade da água tratada (Clark \& Coyle, 1989).

O efeito da mistura de água de diferentes fontes, tais como uma combinação de poços, fontes superficiais ou ambos, pode influenciar muito a qualidade da água na rede. A irregula- ridade do abastecimento na rede de uma determinada área urbana pode também modificar a qualidade da água tratada com a introdução de agentes patogênicos na rede de distribuição (Barcelos et al., 1998).

Nos países em desenvolvimento, em virtude das precárias condições de saneamento e da má qualidade das águas, as doenças diarréicas de veiculação hídrica, como, por exemplo, febre tifóide, cólera, salmonelose, shigelose e outras gastroenterites, poliomielite, hepatite A, verminoses, amebíase e giardíase, têm sido responsáveis por vários surtos epidêmicos e pelas elevadas taxas de mortalidade infantil, relacionadas à água de consumo humano (Leser et al., 1985).

Outro composto importante para a saúde humana cada vez mais encontrado em água de poços é o nitrato. Este íon geralmente ocorre em baixos teores nas águas superficiais, mas pode atingir altas concentrações em águas profundas. O seu consumo por meio das águas de abastecimento está associado a dois efeitos adversos à saúde: a indução à metemoglobinemia, especialmente em crianças, e a formação potencial de nitrosaminas e nitrosamidas carcinogênicas (Bouchard et al., 1992).

O desenvolvimento da metemoglobinemia a partir do nitrato nas águas potáveis depende da conversão bacteriana deste para nitrito durante a digestão, o que pode ocorrer na saliva e no trato gastrointestinal (AWWA, 1990; Mato, 1996).

As crianças pequenas, principalmente as menores de três meses de idade, são bastante suscetíveis ao desenvolvimento desta doença por causa das condições mais alcalinas do seu sistema gastrointestinal (Oliveira et al., 1987), fato também observado em pessoas adultas que apresentam gastroenterites, anemia, porções do estômago cirurgicamente removidas e mulheres grávidas (Bouchard et al., 1992).

A disposição de efluentes industriais contendo metais pesados em fontes hídricas é o maior fator antropogênico, responsável pela poluição em vários ambientes aquáticos. A natureza geoquímica do solo é importante fator causal de poluição por metais, particularmente em fontes de águas subterrâneas. Metais pesados em água persistem por mais tempo que poluentes e percolam da superfície para a camada subterrânea de água (Pathak et al., 1994).

Metais no sistema de distribuição de água podem ter origem na variabilidade da qualidade da água que o sistema de distribuição pode apresentar ou estar relacionados a esse fato.

Duas origens podem ser indicadas: a primeira diz respeito ao próprio sistema que fornece o metal, principalmente por meio de cor- 
rosão química ou microbiológica; a segunda fonte diz respeito à origem da água que entra na estação de tratamento, onde principalmente alumínio e ferro formam compostos utilizados no processo de coagulação cujo objetivo é a remoção de partículas em suspensão na água que aflui para a estação de tratamento.

Metais na água são absorvidos pelo organismo humano através do trato gastrintestinal. Esta absorção pode ser afetada pelo $\mathrm{pH}$, pelas taxas de movimentação no trato digestivo e pela presença de outros materiais; combinações particulares desses fatores podem contribuir para fazer a absorção de metais ser muito alta ou muito baixa no homem.

Os efeitos tóxicos dos metais podem expressar-se de forma aguda ou crônica. Dentre os mecanismos de toxicidade dos metais estão incluídas as interações com sistemas enzimáticos, interações com membranas celulares e efeitos específicos sobre certos órgãos e sobre o metabolismo celular em geral (Goyer, 1986).

Apesar de a concentração de alumínio na água ser controlada por aspectos organolépticos, existe um considerável debate no círculo médico relatando o papel deste metal na incidência do mal de Alzheimer, que é uma doença cerebral degenerativa de etiologia desconhecida caracterizada pela presença de um grande número de estruturas neurofíbrilares e placas senis em certas regiões do cérebro (Perl, 1988). O alumínio é um composto neurotóxico que, a longo prazo, pode causar encefalopatia grave em pacientes que sofrem diálise renal, podendo levar à distúrbios neurológicos.

A natureza da associação entre os depósitos de alumínio no cérebro, a neuroquímica da formação de placas e o mal de Alzheimer ainda é motivo de investigações. No entanto, em virtude da presença de alumínio em água potável ser mais prontamente disponível para absorção biológica que outras fontes, assumiu-se que o alumínio em água potável teria um efeito desproporcional sobre o mal de Alzheimer (Reiber et al., 1995).

Este projeto faz parte do Projeto de Avaliação dos Impactos sobre a Saúde e Qualidade de Vida (PAISQUA) do Programa de Despoluição da Baía de Guanabara (PDBG), executado pelo Núcleo de Estudos de Saúde Coletiva da Universidade Federal do Rio de Janeiro (NESC-UFRJ) (NESC, 1995). Ele também se insere no programa de avaliação da saúde ambiental da Região Metropolitana do Rio de Janeiro, conduzido pelo Departamento de Saneamento e Saúde Ambiental da Escola Nacional de Saúde Pública da Fundação Oswaldo Cruz (DSSA-ESNPFIOCRUZ).
Os objetivos deste artigo são: apresentar os resultados sobre a qualidade da água de poço e de rede (enfoque para coliformes fecais, nitrato e alumínio) consumida no período de outubro de 1996 até setembro de 1998 pela população do Parque Fluminense, em Duque de Caxias, e Colubandê, em São Gonçalo, e revelar os riscos à saúde dos consumidores desses dois tipos de águas, com base nos padrões de potabilidade estabelecidos na Portaria 36/90 do Ministério da Saúde (Brasil, 1990).

\section{Área de estudo}

A área de estudo está situada na Região Metropolitana do Rio de Janeiro. A Figura 1 mostra um mapa geral das regiões estudadas.

O Parque Fluminense é uma região situada no Município de Duque de Caxias, compreende uma parte do distrito de Campos Elísios e foi delimitada e nomeada pelo PDBG e Secretaria de Obras e Serviço Público, da Companhia de Abastecimento de Água do Estado do Rio de Janeiro (CEDAE) para obras de construção e ampliação do sistema de distribuição e armazenamento de água.

O sítio é limitado ao norte pelo Canal do Iguaçu, (com nascente localizada na Serra de São Pedro e Tinguá) e ao sul pelo Canal de Sarapuí (com nascente localizada no Maciço da Pedra Branca, recebendo também contribuições de rios que nascem na Serra do Mendanha); a Baía de Guanabara e o Município de Belfort Roxo são os limites a leste e a oeste, respectivamente.

De acordo com o censo de 1991 (IBGE, 1991), a região possui uma população de 59.300 habitantes, vivendo em um estado precário em termos de condições sanitárias e de higiene no que se refere a água, esgoto e lixo.

O abastecimento de água é feito para $67,29 \%$ dos domicílios através de rede geral, e os restantes, $32,27 \%$ são abastecidos por poços ou nascentes. A região possui uma rede coletora de esgotos que atende somente uma pequena parte da população. A maioria do esgoto é lançada em valas negras e em córregos que cortam a região. Fossas e sumidouros são também muito freqüentes.

A coleta de resíduos sólidos também não é regular, existindo inúmeros pontos críticos de lixo em vários pontos da região.

O Colubandê possui uma população de 95.036 habitantes e 26.400 domicílios de acordo com o censo demográfico de 1991 (IBGE, 1991). É um dos cinco distritos do Município de São Gonçalo. O município limita-se, ao norte, com Itaboraí, ao sul, com Niterói e Maricá, a 

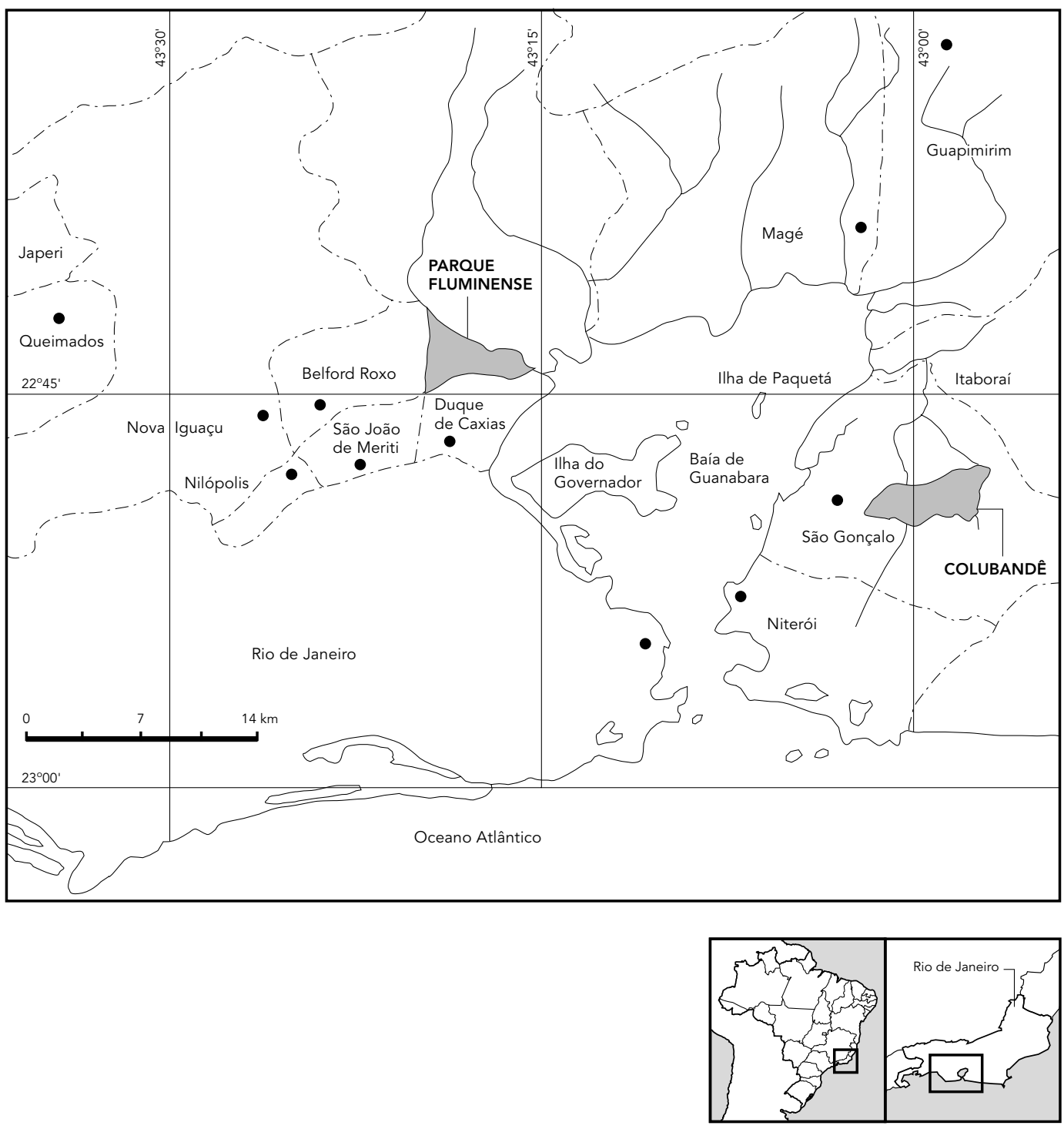

leste, Maricá e, a oeste, com a Baía de Guanabara. O abastecimento de água é feito para $64,23 \%$ dos domicílios através de rede geral, e os restantes $35,7 \%$ são abastecidos por poços ou nascentes. Quanto ao esgotamento sanitário, 8,89\% dos domicílios estão ligados à rede geral, sendo predominante o uso de fossa rudimentar, $78,7 \%$.

Ambas as regiões de estudo apresentam grandes problemas no abastecimento de água potável onde a regularidade do fornecimento é intermitente, levando as comunidades da área optarem por abastecimento alternativo, tais como perfuração, escavação de poços e a execução de ligações não oficiais, conectadas à rede de distribuição da companhia fornecedora do Estado.

\section{Metodologia}

As áreas de amostragem foram delimitadas por setores censitários. Estes setores são definidos e utilizados pela Fundação Instituto Brasileiro de Geografia e Estatística (IBGE) e fornecem uma 
base de dados de indicadores sócio-econômicos e de saúde. No Parque Fluminense foram selecionados 14 setores e no Colubandê, 22 .

Os pontos de coleta foram selecionados com base em critérios ambientais e sanitários, partindo da análise das plantas do sistema de distribuição de água fornecida pela CEDAE, dos dados do censo do IBGE de 1991 e dos resultados do inquérito epidemiológico realizado pelo PAISQUA. Quatro áreas de influência foram delimitadas: (1) área com cotas altimétricas altas; (2) áreas próximas a esgotamento in natura, como canais e valões; (3) áreas mais distantes da adutora principal; e (4) áreas com maior número de poços e que apresentam também maiores riscos (número de valas negras, número de domicílios que não possuem esgotamento adequado para suas águas residuárias e número de fossas sépticas sem escoadouro adequado).

As amostras de água de rede foram coletadas visando obter dois tipos de informações sobre a regularidade de abastecimento do sistema. Inicialmente, foram coletadas amostras da torneira de entrada do usuário. Caso não houvesse água saindo deste ponto primário de entrada de água da rede, a amostra era coletada na saída da caixa d'água ou cisterna. Desta forma, os domicílios que mais ofereceram água da torneira de entrada apresentariam também uma maior regularidade no fornecimento de água.

Todos os domicílios onde amostras de água foram coletadas possuíam poço e ligação no sistema de distribuição de água.

A escolha do número de poços e de pontos do sistema de distribuição levou em conta a capacidade analítica mensal do laboratório de análise e a disponibilidade de transporte para coleta.

No Parque Fluminense foram selecionados ao todo quarenta pontos fixos ou domicílios distribuídos pelos setores censitários, sendo vinte pontos para amostras de água de rede e vinte pontos para coleta de água de poço. No Colubandê foram selecionados quarenta pontos para amostras de água de rede e dez para água de poço. As coletas foram realizadas entre outubro de 1996 e setembro de 1998 e foram organizadas de forma que, pelo menos, uma amostra de água de cada ponto fosse coletada por mês.

As amostras de água nas torneiras e nas saídas das bombas dos poços foram coletadas após deixar a água escorrer por três minutos. A sistemática de coleta e de preservação das amostras seguiu a metodologia proposta no Standard Methods for the Examination of Water and Wastewater (APHA, 1992).
$\mathrm{O}$ pH foi medido, utilizando-se um medidor de pH de campo modelo Corning PS 30. O medidor de $\mathrm{pH}$ foi calibrado com soluções tamponadas de $\mathrm{pH} 4,0$ e 7,0.

As análises de nitrato foram realizadas através de método colorimétrico, usando o kit Hach Nitraver CN66.

As análises de coliformes totais e fecais para os anos de 1996 e 1997 foram realizadas através de membrana filtrante com contagem de coliformes. No ano de 1998 foram realizados somente os testes de ausência e presença de coliformes.

Todas as análises bacteriológicas foram realizadas no Laboratório de Central de Saúde Pública Noel Nutels (LACEN).

As análises de metais foram realizadas no Laboratório do Instituto de Biofísica Carlos Chagas Filho da Universidade Federal do Rio de Janeiro. A metodologia analítica utilizada foi: as amostras previamente acidificadas com $2 \mathrm{ml}$ de ácido clorídrico concentrado, $\mathrm{HCl}$, foram evaporadas em um bécher, em placa de aquecimento, onde o volume inicial foi reduzido em cerca de cem vezes. Em seguida, as mesmas foram transferidas para um cadinho de teflon e colocadas em banho de areia, onde foram submetidas a um ataque ácido $\mathrm{HNO}_{3}+$ $\mathrm{HClO}_{4}$ (1:3), seguido de fluoração com ácido fluorídrico. As amostras foram, posteriormente, levadas à secura, seguida de ataque com $\mathrm{HCl}$ concentrado, e, novamente, levadas à secura e, finalmente, retomadas com $\mathrm{HCl} 0,1 \mathrm{M}$. No volume final de aproximadamente $50 \mathrm{ml}$, efetuou-se a determinação da concentração dos metais.

As leituras foram realizadas em um aparelho de absorção atômica, usando um modelo Varian AA1475. Padrões internos foram usados para verificar possíveis interferências. Os reagentes utilizados foram Merck, p.a., incluindo padrões de metais (Tritrisol). Brancos de reagentes foram efetuados com a mesma quantidade de reagentes utilizados nas amostras. As concentrações de metais foram determinadas em triplicatas e, para cada processo, foi sempre executado um branco junto com as amostras.

\section{Resultados}

Durante a execução deste projeto, ocorreram alguns problemas operacionais, como a importação de reagentes e eletrodos utilizados nas análises físico-químicas, o que ocasionou uma certa implicação sobre a periodicidade e o número de amostras coletadas. O resultado das análises de nitrato em água de poços obtidas 
no Parque Fluminense é apresentado na Figura 2. Nessa área, 46 amostras foram analisadas, cobrindo o período de junho a outubro de 1997.

No total, $30,4 \%$ das amostras apresentaram valores superiores ao padrão da Portaria do Ministério da Saúde 36/90 (Brasil, 1990), que é de $10 \mathrm{mg} / \mathrm{l}\left(\mathrm{N}-\mathrm{NO}_{3}^{-}\right)$. No Colubandê, somente uma amostra apresentou resultado acima do padrão da Portaria 36/90. Vale ressaltar que somente dois dos dez poços da área foram amostrados. Estes resultados representam um risco para a saúde da população local, uma vez que vários trabalhos associam o consumo de água contendo altas concentrações de nitrato ao aparecimento da metemoglobinemia, especialmente em crianças, e à formação potencial de nitrosaminas e nitrosamidas carcinogênicas.

Alguns autores (Alaburda \& Nishihara, 1998), consideram que concentrações superiores a $3 \mathrm{mg} \mathrm{N}-\mathrm{NO}_{3}^{-} / \mathrm{l}$ em amostras de água são indicativos de contaminação por atividades antropogênicas. No caso do Parque Fluminense, $60,85 \%$ das amostras analisadas se enquadram nesta situação.

Em somente uma amostra de água de rede nas duas regiões foi encontrado resultado superior ao padrão da Portaria 36/90 (Brasil, 1990). Portanto, com relação a nitrato em água de rede, podemos considerar que os níveis estavam em conformidade com a norma. O único valor diferente pode ser fruto de uma contaminação localizada.

Figura 2

Porcentagem das concentrações de nitrato que ultrapassaram o padrão (10 mg/l N-NO- ). Parque Fluminense, junho/1997 a outubro/1997.

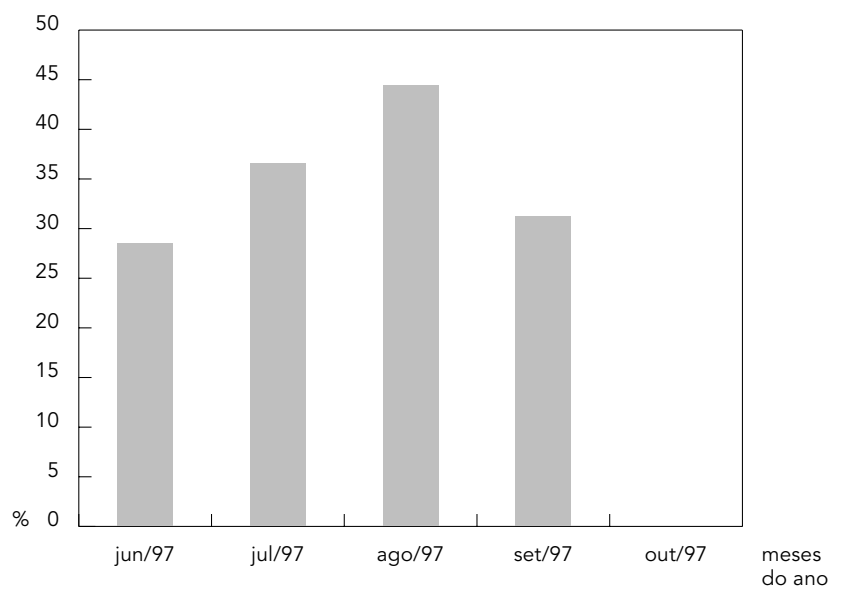

Em água de poço, o indicativo da presença de contaminação antropogênica pelas elevadas concentrações de nitrato é também comprovado pelos resultados das análises bacteriológicas.

No Parque Fluminense, foram analisadas 225 amostras de água. Em 131, realizou-se a contagem de coliformes pelo método de filtração por membrana, sendo que, em 1994, verificou-se somente a presença ou ausência de organismos coliformes. O período amostrado foi de outubro de 1996 a setembro de 1998. Das amostras analisadas, $55,5 \%$ apresentaram presença de coliformes fecais, indicando impropriedade dessas águas para o consumo humano, de acordo com a Portaria 36/90 (Brasil, 1990). Dados por poço mostraram que $99,3 \%$ das amostras coletadas ao longo do período, no mesmo poço, apresentaram valores de coliformes fecais insatisfatórios. Do total de amostras analisadas, 5,3\% apresentaram índices de coliformes fecais iguais a 1.600 por $100 \mathrm{ml}$.

No Colubandê, a porcentagem de amostras que apresentaram resultados de coliformes fecais impróprios para o consumo humano foi de $62 \%$.

Este quadro reflete a situação de risco em que se encontra a maioria dos mananciais subterrâneos das áreas estudadas. Estas áreas apresentam uma grande densidade urbana e demográfica, não possuem rede coletora de esgotos, fazendo, portanto, uso de fossas, sumidouros e valas negras como destino final para seus dejetos. Os resultados de colimetria também indicam que a contaminação por nitratos no Colubandê pode ser maior que a encontrada, uma vez que somente dois poços foram amostrados, um quadro pouco representativo dos dez poços onde amostras de colimetria foram analisadas.

Em relação à água do sistema de distribuição, a Figura 3 mostra as porcentagens de coliformes fecais presentes em água de rede e de caixa d'água do Colubandê e do Parque Fluminense.

Verificamos que, no Colubandê, $6,2 \%$ das amostras analisadas e, no Parque Fluminense, $6,6 \%$, encontraram-se fora dos parâmetros da Portaria 36/90 (Brasil, 1990). Este alto percentual de contaminação pode ser atribuído à intermitência do sistema, que favorece a entrada de água contaminada no interior da tubulação vazia, em áreas de pressão negativa. Isto também pode indicar uma contaminação eventual e pontual, uma vez que a rede de distribuição encontra-se, em diversos locais, com perfurações clandestinas.

Em relação à água coletada na saída da caixa ou cisterna do domicílio, verifica-se um au- 
mento bastante significativo de amostras contaminadas.

Estes resultados evidenciam que a contaminação da água pode ocorrer no próprio domicílio, por falta de manutenção do reservatório, pela sua localização, pela ausência de cuidados com o manuseio e higiene e, também, pelo tipo de material que é empregado na construção da cisterna ou caixa d'água.

A variação da concentração de cloro residual livre e do pH em água coletada na rede de distribuição do Parque Fluminense é mostrada na Tabela 1.

De acordo com a Tabela 1, os resultados de cloro residual mostraram que, na rede do Parque Fluminense, 5,04\% das amostras apresentaram concentrações de cloro residual iguais a zero, isto é, inferiores ao recomendado pela Portaria 36/90 (Brasil, 1990), que é de 0,2mg/l. Além disso, 91,6\% das amostras apresentaram concentrações maiores ou iguais a $0,2 \mathrm{mg} / \mathrm{l}$. Em água de caixa d'água, por sua vez, $42,42 \%$ das amostras apresentaram cloro residual livre igual a zero e 53,53\% apresentaram concentrações maiores ou iguais a $0,2 \mathrm{mg} / \mathrm{l}$. No Colubandê, em água de rede, $6,5 \%$ apresentaram valores iguais a zero, e $91,97 \%$, valores maiores que $0,2 \mathrm{mg} / \mathrm{l}$. Em água de caixa d'água, $32,90 \%$ apresentaram valores iguais a zero, e $59,35 \%$, concentrações maiores que $0,2 \mathrm{mg} / \mathrm{l}$.

Estes valores de cloro residual livre justificam o aumento da presença de coliformes fecais em água de caixa d'água e de rede. Os altos valores de cloro residual encontrados nessas duas áreas, se, por um lado, podem ter um efeito benéfico contra bactérias e vírus, podem também apresentar outros problemas de saúde para a população.

Uma característica geral do $\mathrm{pH}$ médio nessas duas áreas foi a acidez. Os resultados encontrados na Tabela 1 mostram que $51 \%$ das amostras apresentaram $\mathrm{pH}$ inferior a 6,5, estando, portanto, em desacordo com o recomendado pela Portaria, que estabelece o intervalo de 6,5 a 8,5 como o recomendado. Quando analisamos os dados para $\mathrm{pH}$ inferior a 7, essa porcentagem sobe para $79,7 \%$ das amostras. No

Figura 3

Porcentagem de amostras contaminadas com coliformes fecais para água tratada (rede e caixa d'água). Colubandê e Parque Fluminense, março/1997 a outubro/1998.

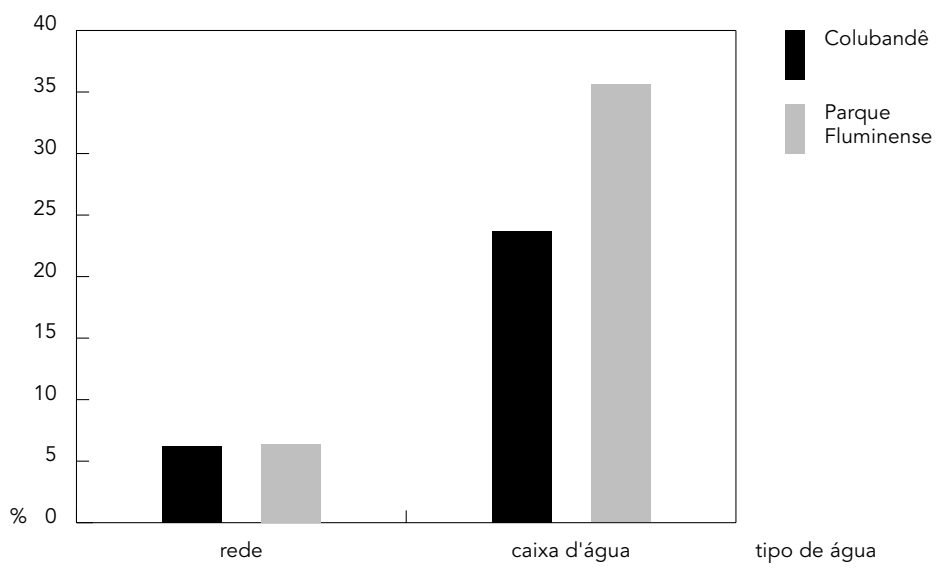

Cloro residual livre e $\mathrm{pH}$ em água de rede para o Parque Fluminense e Colubandê.

\begin{tabular}{|c|c|c|c|c|c|c|c|}
\hline & Média & Máximo & Mínimo & Desvio-padrão & $\%<6,5$ & $\% \geq 6,5$ e $\leq 8,5$ & Período de análise \\
\hline \multicolumn{8}{|l|}{ Parque Fluminense } \\
\hline \multirow[t]{2}{*}{$\mathrm{pH}-$ rede $(\mathrm{n}=84)$} & 6,23 & 7,74 & 4,9 & 0,8099 & 51,19 & 48,81 & $28 / 10 / 96-13 / 04 / 98$ \\
\hline & & & & & $\%=0$ & $\% \geq 0,2$ & \\
\hline Cloro livre -rede $(\mathrm{n}=238) \mathrm{mg} / \mathrm{l}$ & 2,04 & 3,5 & 0 & 1,132 & 5,04 & 91,6 & $28 / 10 / 96-30 / 09 / 98$ \\
\hline \multirow[t]{2}{*}{ Cloro livre -caixa d'água $(n=99) \mathrm{mg} / \mathrm{l}$} & 0,82 & 3,5 & 0 & 1,063 & 42,42 & 53,53 & 04/01/96-02/09/98 \\
\hline & & & & & $\%=0$ & $\% \geq 0,2$ & \\
\hline \multicolumn{8}{|l|}{ Colubandê } \\
\hline \multirow[t]{2}{*}{$\mathrm{pH}-$ rede $(\mathrm{n}=35)$} & 6,86 & 7,65 & 5,09 & 0,7172 & 20 & 80 & $30 / 03 / 97-01 / 04 / 98$ \\
\hline & & & & & $\%<6,5$ & $\% \geq 6,5$ e $\leq 8,5$ & \\
\hline Cloro livre rede $(n=137) \mathrm{mg} / \mathrm{l}$ & 1,16 & 3,00 & 0,00 & 0,6396 & 6,5 & 91,97 & $30 / 03 / 97-25 / 09 / 98$ \\
\hline Cloro livre caixa d'água $(n=155) \mathrm{mg} / \mathrm{l}$ & 0,377 & 2,5 & 0 & 0,4166 & 32,9 & 59,35 & 04/04/97-20/10/98 \\
\hline
\end{tabular}


Colubandê, $20 \%$ das amostras apresentaram pH inferior a 6,5, e 45,7\%, inferior a 7 .

Estes valores, embora sejam favoráveis para aumentar a ação bactericida do cloro residual por formar uma porcentagem importante de $\mathrm{HOCl}$, o qual é extremamente eficaz contra microorganismos, apresenta um risco importante de agressividade contra os materiais que constituem as tubulações, não somente diminuindo a vida útil dos mesmos, mas, sobretudo, podendo deteriorar a qualidade da água tratada, pela dissolução de produtos oriundos da própria corrosão e/ou do meio externo, como conseqüência da quebra da estanqueidade das tubulações.

Os resultados de metais para água de poço apontam o alumínio, o manganês e o ferro como os metais que apresentaram valores acima do preconizado na Portaria 36/90 (Brasil, 1990). Destes, o alumínio apresentou resultados superiores aos da Portaria em $100 \%$ das amostras analisadas em todas as duas áreas estudadas (Figura 4).

A presença de concentrações de alumínio, manganês e ferro em água de poço com valores acima dos da Portaria 36/90 (Brasil, 1990) pode ser entendida como tendo origem natural. No entanto, pode estar sendo provocada pela poluição antropogênica em conseqüência da presença de lixões, valas negras e grande número de fossas na região. A composição deste cenário pode levar a uma contaminação do lençol freático, pelo líquido que percola através do solo e que é proveniente tanto dos lixões (no caso, o chorume) como do próprio esgoto in natura liberado pelas fossas e valas da região. Estes líquidos, ao entrar em contato com o lençol subterrâneo, podem alterar o pH do meio, mobilizando metais, os quais, contidos naturalmente no solo, passam para a forma dissolvida na água.

Em água de rede, as análises mostram somente o alumínio como o metal que se apresenta com valores acima dos padrões estabelecidos na Portaria 36/90 (Brasil, 1990). A Figura 4 mostra os resultados do alumínio em água de rede para as regiões estudadas. Nela podemos observar que, no Colubandê, $100 \%$ das amostras apresentaram concentrações de alumínio superiores ao padrão da Portaria 36/90, e, no Parque Fluminense, esse valor foi de $75 \%$.

A constatação da presença de alumínio em água de rede pode ocorrer em função de fatores como: falhas no sistema de tratamento da água quando se usa coagulantes a base de alumínio ou mistura de águas que não sofreram um tratamento completo.

No Parque Fluminense, onde parte da rede recebe água do sistema Acari, sujeito a varia- ções sazonais de qualidade, pois recebe apenas dois tipos de tratamento (pré-decantação e desinfecção), é possível que o alumínio encontrado na água da torneira de entrada das casas possa ser proveniente desses processos. No Colubandê, a água provém do sistema ImunanaLaranjal, que passa por uma seqüência completa de tratamento, incluindo coagulação com sais metálicos, como o sulfato de alumínio.

\section{Conclusão}

Este trabalho mostrou que, a despeito dos problemas relativos a periodicidade de coleta e número reduzido de amostras para avaliação de alguns parâmetros, os resultados obtidos fornecem um quadro da qualidade da água consumida nessas áreas nos períodos analisados.

Com relação à água de poço das duas áreas, os resultados, quando comparados com os padrões de potabilidade da Portaria 36/90 do Ministério da Saúde (Brasil, 1990), mostraram que, no Parque Fluminense, 30,4\% das amostras de nitrato encontram-se em desacordo com a referida Portaria. Em água de poço, $55,5 \%$ das amostras do Parque Fluminense e $62 \%$ do Colubandê apresentaram índices de coliformes fecais acima dos padrões estabelecidos na Portaria e, em água de rede, os valores foram $6,2 \%$ para o Parque Fluminense e 6,6\% para o Colubandê. A elevada porcentagem de amostras com cloro residual igual a zero na rede de distribuição, e, mais ainda, na água de caixa d'água, indicam a existência de problemas de manutenção e operação da rede de distribuição e das próprias caixas d'água. Os resultados de pH encontrados nas duas áreas também mostram que os materiais das redes de distribuição podem estar sendo afetados pela acidez das águas distribuídas. No Parque Fluminense, 51\% das amostras e, no Colubandê, $20 \%$ apresentaram valores de $\mathrm{pH}$ inferior a 6,5, sendo, portanto, inferiores ao intervalo recomendado pela Portaria 36/90 (Brasil, 1990). Com relação ao alumínio, $100 \%$ das amostras de água de poço nas duas regiões e na água de rede do Colubandê apresentaram valores em desacordo com a Portaria do Ministério da Saúde. Na água de rede do Parque Fluminense, $75 \%$ das amostras analisadas estavam fora dos padrões estabelecidos pela Portaria.

Estes valores acima do que se preconiza na Portaria 36/90 (Brasil, 1990), tanto para parâmetros bacteriológicos quanto para físico-químicos, colocam a população consumidora exposta a diversos riscos para a saúde, como: 


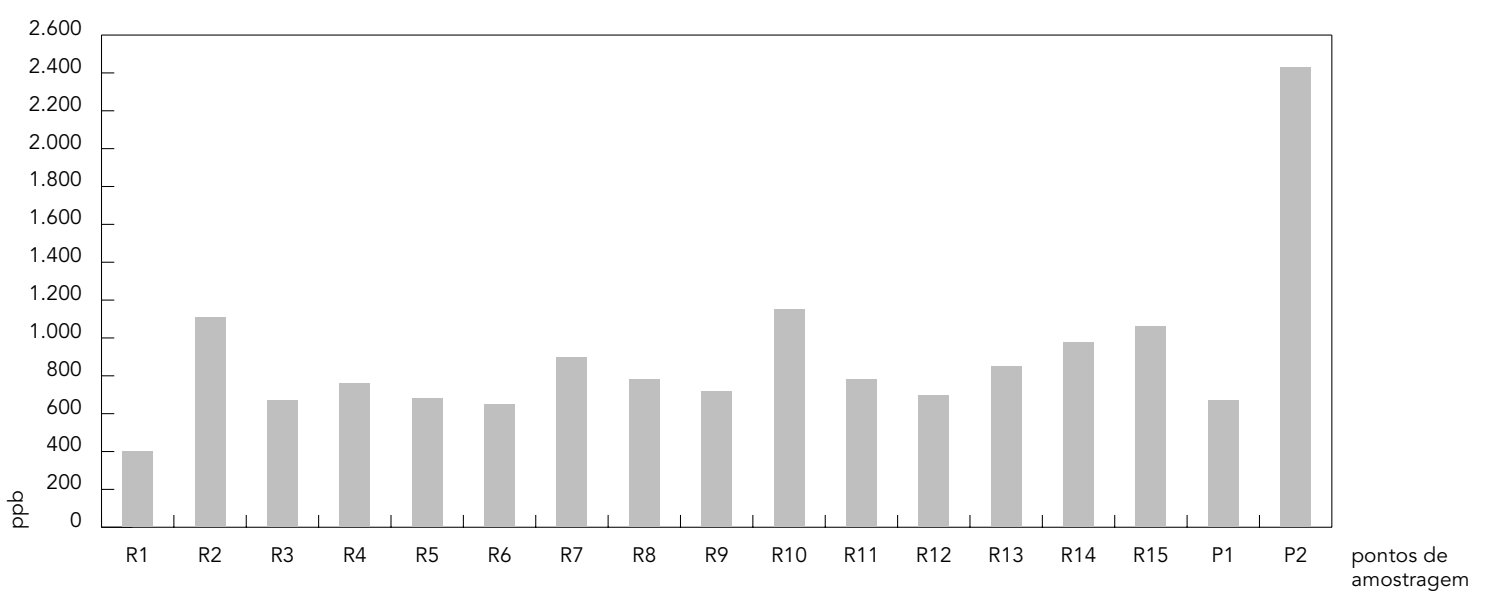

Figura $4 b$

Concentração de alumínio em água de poço e rede. Parque Fluminense (dezembro/1996).

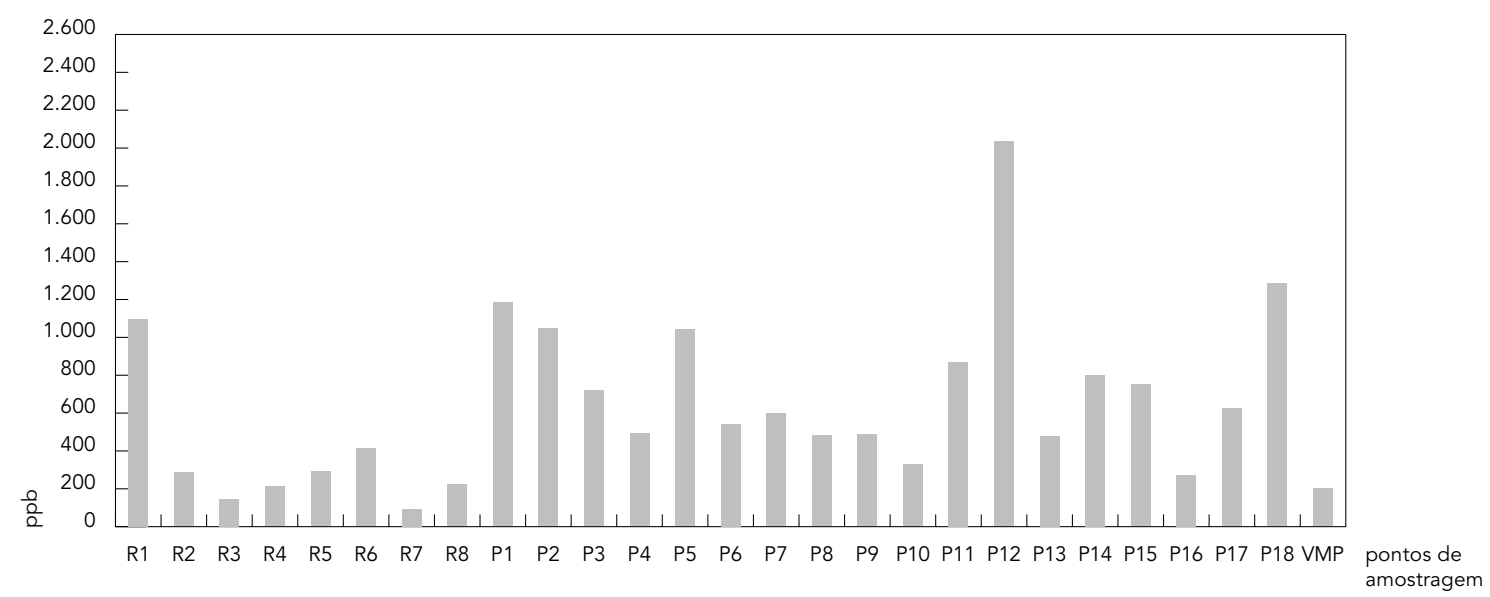

doenças de veiculação hídricas com relação à qualidade bacteriológica; possibilidade de casos de metemoglobinemia em crianças; formação de nitrosaminas e nitrosamidas cancerígenas, pelo consumo de água de poço com elevadas concentrações de nitrato; e possível aumento dos casos do mal de Alzheimer, pelo consumo de água contendo alumínio acima da norma nacional. Em relação ao alumínio, vale salientar que, nos Estados Unidos, a concentração permitida em água tratada e distribuída é dez vezes inferior à da Portaria 36/90 (Brasil, 1990).

Acreditamos que o risco à saúde da população seria diminuído se, em primeiro lugar, a regularidade do suprimento de água potável e a manutenção do sistema de distribuição fossem melhoradas. Em segundo lugar, a qualidade da água natural do sistema Acari deve ser monitorada mais de perto, assim como a concentração de alumínio distribuída nos outros sistemas deve estar em conformidade com a Portaria. 
Para os domicílios que não dispõem de sistema de distribuição, estes devem ser notificados dos problemas de potabilidade de suas águas para consumo e algum tipo de tratamento ou substituição da fonte de suprimento deve ser providenciado.

\section{Referências}

ALABURDA, J. \& NISHIHARA, L., 1998. Presença de compostos de nitrogênio em águas de poços. $R e$ vista de Saúde Pública, 32:160-165.

APHA (American Public Health Association), 1992. Standard Methods for the Examination of Water and Wastewater. Washington, DC: APHA.

AWWA (American Water Works Association), 1990. Water Quality and Treatment: A Handbook of Community Water Supplies. New York: Mcgraw Hill.

BARCELLOS, C.; COUTINHO, K.; PINA, M. F.; MAGALHÃES, M. M. A. E.; PAOLA, J. C. M. D. \& SANTOS, S. M., 1998. Inter-relacionamento de dados ambientais e de saúde: Análise de riscos à saúde aplicada ao abastecimento de água no Rio de Janeiro utilizando sistemas de informações geográficas. Cadernos de Saúde Pública, 14:597-605.

BOUCHARD, D. C.; WILLIAMS, M. D. \& SURAMPALLI, R. Y., 1992. Nitrate contamination of ground water sources and potential health effects. Journal of the American Water Works Association, 84:85-90.

BRASIL, 1990. Portaria 36/90. Padrão de Potabilidade da Água Destinada ao Consumo Humano. Brasília: Ministério da Saúde.

CLARK, R. M. \& COYLE, J. A., 1989. Measuring and modeling variations in distributions systems water quality. Journal of the American Water Works Association, 82:46-52.

DEININGER, R. A.; CLARK, R. M.; HESS, A. F. \& BERNSTAM, E. V., 1992. Animation and visualization of water quality in distribution systems. Journal of the American Water Works Association, 84:48-52.

FREITAS, M. B. \& ALMEIDA, L. M., 1998. Qualidade da água subterrânea e sazonalidade de organismos coliformes em áreas densamente povoadas com saneamento básico precário. In: X Congresso Brasileiro de Águas Subterrâneas. CD-ROM, São Paulo: Sonopress-Rimo.

GOYER, R. A., 1986. Toxic effects of metals. In: Casarett \& Doull's Toxicology: The Basic Science of Poisons (L. J. Casarett, C. D. Klaassen, K. Klaassen \& J. Watkins, ed.), pp. 582-635, New York: Macmillan Publishing Company.

IBGE (Fundação Instituto Brasileiro de Geografia e Estatística), 1991. Censo Brasileiro de 1991. Rio de Janeiro: IBGE.
IBGE (Fundação Instituto Brasileiro de Geografia e Estatística), 1994. Dados sobre Domicílios no Estado do Rio de Janeiro. Anuário Estatístico do Brasil, v. 54. Rio de Janeiro: IBGE.

LESER, W. S.; BARBOSA, V.; BARUZZI, R. G.; RIBEIRO, M. D. B. \& FRANCO, L. J., 1985. Elementos de Epidemiologia Geral. São Paulo: Atheneu.

MATO, A. P., 1996. Determinação de Nitratos, Nitritos e Prováveis Fontes de Contaminação em Águas de Poços e sua Influência na Metemoglobinemia Infantil. Dissertação de Mestrado, São Paulo: Universidade Mackenzie.

NESC (Núcleo de Estudos de Saúde Coletiva), 1995 Projeto de Avaliação dos Impactos de Despoluição da Baía de Guanabara sobre as Condições de Saúde e Qualidade de Vida - PAISQUA. Rio de Janeiro: Núcleo de Estudos de Saúde Coletiva, Universidade Federal do Rio de Janeiro.

NORDBERG, G. F.; GOYER, R. A. \& CLAKSON, T. W. 1985. Impact of effects of acid precipitation on toxicity of metals. Environmental Health Perspectives, 63:169-180.

OLIVEIRA, J. J. V.; VALILO, M. I.; PEDRO, N. A. R. \& ZENEBON, O., 1987. Estudo comparativo de métodos para determinação de nitrato em águas naturais. Revista do Instituto Adolfo Lutz, 47:25-30.

PATHAK, S. P.; KUMAR, S.; RAMTEKE, P. W.; MURTHY, R. C.; BHATTACHERJEE, J. W. \& GOPAL, K., 1994. Potability of water sources in relation to metal and bacterial contamination in some northern and northern-eastern districts of India. Environmental Monitoring and Assessment, 33: 151-160.

PERL, D. P. \& GOOD, P. F., 1988. Aluminum, environmental and central nervous system disease. Environmental Technology Letters, 9:901-906.

REIBER, S.; KUKULL, W. \& STANDISH-LEE, P., 1995. Drinking water aluminum and bioavailability. Journal of the American Water Works Association, 87:86-99. 